\title{
Evolução dos Níveis de Aplicação de Relatórios de Sustentabilidade (GRI) de Empresas do ISE/Bovespa
}

\section{Evolution of Application Level Sustainability Reporting (GRI) Companies ISE / Bovespa}

\author{
Rosany Corrêa \\ Doutoranda em Administração de Empresas - Universidade Nove de Julho \\ Professora da Universidade Estadual do Piauí, Campus Torquato Neto, Teresina - PI \\ Avenida Francisco Matarazzo, 612, prédio C, Água Branca, São Paulo - SP - 05001-100 \\ rosanycorrea@hotmail.com \\ Maria Tereza Saraiva de Souza \\ Doutora em Administração de Empresas pela Fundação Getúlio Vargas (SP) \\ Professora do PMDA da Universidade Nove de Julho \\ Avenida Francisco Matarazzo, 612, prédio C, Água Branca, São Paulo - SP - 05001-100 \\ mtereza@uninove.br \\ Henrique César Melo Ribeiro \\ Doutorando em Administração de Empresas pela Universidade Nove de Julho \\ Professor da Faculdade Piauiense, Campus de Parnaíba - PI \\ Avenida Francisco Matarazzo, 612, prédio C, Água Branca, São Paulo - SP - 05001-100 \\ hcmribeiro@hotmail.com \\ Mauro Silva Ruiz \\ Doutor em Filosofia pela Universidade de Ilinois - EUA \\ Professor do PMDA da Universidade Nove de Julho \\ Avenida Francisco Matarazzo, 612, prédio C, Água Branca, São Paulo - SP - 05001-100 \\ maurosilvaruiz@gmail.com
}

\section{Resumo}

O presente trabalho trata da adoção e evolução dos níveis de relatórios de sustentabilidade (GRI). Os objetivos específicos foram: verificar o nível de evolução dos relatórios da GRI nas empresas do mundo; verificar o nível de evolução dos relatórios da GRI nas empresas do Brasil; analisar a estrutura e nível de aplicação dos relatórios da GRI nas empresas atuantes no ISE da BM\&FBovespa. A GRI tem suas bases de relatórios na terceira geração do modelo, GRI-G3, o que mostra um empenho na melhoria contínua dos indicadores e sua adoção por diferentes países. A metodologia utilizada foi qualitativa, por meio de levantamento bibliográfico e dados secundários. Como instrumento de análise adotou-se a Report List GRI 2011. A análise evidenciou uma evolução significativa na adoção ao modelo GRI pelas empresas nos três níveis, mundo, Brasil e Índice de Sustentabilidade Empresarial. Os resultados da pesquisa mostram a evolução dos níveis desses relatórios, na busca do nível mais aprimorado GRI A, e com adoção significativa no Brasil por verificação aos níveis autodeclarados, o que legitima o modelo de relatório de sustentabilidade da Global Reporting Initiative. Conclui-se que a evolução dos relatórios de sustentabilidade no modelo GRI do ISE 
BM\&FBovespa se consolida como modelo mais utilizado em 30 empresas de um total de 45 em 2010, confirmando-se assim a legitimação desta metodologia.

Palavras-chave: Indicadores de Sustentabilidade. Relatório de Sustentabilidade. Global Reporting Initiative. Índice de Sustentabilidade Empresarial.

\begin{abstract}
This work deals with the adoption and evolution of the levels of sustainability reports (GRI). The specific objectives were to ascertain the level of development of the GRI reporting companies in the world, check the level of development of the GRI reporting companies in Brazil, analyzing the structure and level of application of GRI reports on companies operating in the ISE BM\&F Bovespa. The GRI reporting has its bases in the third generation model, GRI-G3, which shows a commitment to continuous improvement of the indicators and their adoption by different countries. The methodology adopted was qualitative in that article, through literature and secondary data. As an analytical tool adopted de 2011 GRI Report List. The analysis showed a significant development in adopting the GRI model for companies at three levels, world, Brazil and the Corporate Sustainability Index. As well as the evolution of the levels of these reports, in pursuit of improved GRI level A, and with significant adoption in Brazil by checking the self-declared levels, which validates the model of sustainability report of the Global Reporting Initiative. It is concluded that the evolution of sustainability reporting in GRI's BM\&FBovespa ISE consolidates itself as the model most used by 30 companies from a total of 45 in 2010, thus confirming the legitimacy of this methodologically.
\end{abstract}

Keywords: Sustainability Indicators. Sustainability Report. Global Reporting Initiative. Corporate Sustainability Index.

\title{
1 Introdução
}

O desenvolvimento econômico gera não só riqueza, mas também dejetos e degradação ambiental. Medidas são tomadas por governos e por empresas para mitigar os efeitos sobre o meio ambiente. Segundo Sachs (1997), o conceito de desenvolvimento sustentável refere-se a uma nova concepção de limites e reconhecimento das fragilidades do planeta, ao mesmo tempo em que enfoca o problema socioeconômico e da satisfação das necessidades básicas da população. O relatório Nosso Futuro Comum (COMISSÃO MUNDIAL SOBRE O MEIO AMBIENTE E DESENVOLVIMENTO, 1991) define desenvolvimento sustentável como aquele que satisfaz as necessidades do presente sem comprometer a capacidade das gerações futuras de suprir suas próprias necessidades.

Uma organização que adota a responsabilidade socioambiental presta contas de seu desempenho, econômico, ambiental e social, elaborando relatórios de sustentabilidade para divulgar às partes interessadas. Diante deste cenário, surgem modelos de indicadores e de relatórios que orientam a implantação e os controles das empresas que desenvolvem ações de sustentabilidade.

Os relatórios de sustentabilidade que estão em uso no Brasil são o do Instituto Ethos (2011) e o da Global Reporting Initiative - GRI, que apresentou um crescimento significativo na última década em número de empresas que utilizam essa metodologia. O conjunto de diretrizes e indicadores da GRI proporciona a comparabilidade, credibilidade, periodicidade e legitimidade da informação na comunicação do desempenho social, ambiental e econômico das organizações que utilizam a metodologia (GRI, 2006; LEITE FILHO; PRATES; GUIMARÃES, 2009). 
A GRI tem suas bases de relatórios na terceira geração do modelo, GRI-G3, o que mostra um empenho na melhoria contínua dos indicadores e sua adoção por diferentes países. Para indicar que um relatório é baseado na GRI, os relatores devem declarar o nível aplicado à estrutura de relatório. Os níveis fornecem um ponto de partida para organizações que elaboram o relatório pela primeira vez, incentivando e reforçando a importância de uma abordagem progressiva para a elaboração de relatórios que aumenta a exigibilidade ao longo do tempo. Podendo ocorrer de forma autodeclarado ou pela verificação externa. Os três níveis de aplicação do relatório são intitulados A, B e C. Os critérios de relato encontrados em cada um dos níveis indicam a evolução da aplicação ou cobertura da estrutura de relatórios da GRI. Uma organização poderá autodeclarar um ponto a mais (+) em cada nível (por exemplo, C+, $\mathrm{B}+, \mathrm{A}+$ ), caso tenha sido utilizada verificação externa do relatório (GRI, 2006).

Diante do exposto esse estudo se propõe a responder a seguinte questão de pesquisa: quais são os níveis de aplicação de relatórios de sustentabilidade das empresas listadas no ISE/Bovespa comparadas com as empresas do Brasil e do mundo que utilizam as diretrizes da GRI?

O objetivo geral da pesquisa é investigar a evolução dos relatórios de sustentabilidade (GRI) e seus níveis de aplicação das empresas do ISE Bovespa comparados com as demais empresas do Brasil e do mundo. O objetivo geral foi desdobrado nos seguintes objetivos específicos: verificar o nível de evolução dos relatórios da GRI nas empresas do mundo; verificar o nível de evolução dos relatórios da GRI nas empresas do Brasil; analisar a estrutura e nível de aplicação dos relatórios do GRI nas empresas atuantes no ISE da BM\&FBovespa.

Este artigo se divide em cinco partes. A primeira, a introdução, apresenta a justificativa, problema e objetivo de pesquisa; a segunda parte contempla a fundamentação teórica da pesquisa, que discorre sobre sustentabilidade, relatórios de sustentabilidade, ISE e GRI; o método de pesquisa aborda os procedimentos de coleta e tratamento dos dados na parte três; a análise e discussão dos resultados na parte quatro, e, por fim, as considerações finais, que apresenta as principais conclusões, limitações da pesquisa e recomendações para futuros estudos.

\section{Fundamentação Teórica}

O conteúdo da fundamentação teórica contempla os seguintes temas: evidenciação de informações socioambientais; relatórios de sustentabilidade; Global Reporting Initiative (GRI) abordando a forma de gestão e indicadores de desempenho, níveis de aplicação da GRI; e o Índice de Sustentabilidade Empresarial (ISE) da Bovespa.

\subsection{Evidenciação de Informações Socioambientais}

No ambiente empresarial, a imagem da organização tem se tornado preponderante junto a seus stakeholters. As transformações sociais e ambientais que o mundo corporativo passa, sinalizam uma necessidade proeminente de reconhecimento junto à comunidade de ações de transparência nos negócios. Para Azevedo (2006), a incorporação da sustentabilidade no universo empresarial esta condicionada a vários aspectos como as crenças do próprio dirigente da empresa, a mobilização da sociedade, a influência do mercado nacional e internacional, a atuação do setor público, a pressão de organismos internacionais, entre inúmeros outros fatores de ordem conjuntural.

Considerando as concepções diferentes dos ambientalistas sobre a definição das dimensões de sustentabilidade. Sachs (1997) apresenta um conceito evolutivo e dinâmico, que apresenta cinco dimensões, sendo: sustentabilidade social, econômica, ecológica, geográfica e cultural.

Corrêa, R.; Souza, M. T. S.; Ribeiro, H. C. M.; Ruiz, M. S. 
As empresas estão inseridas em um ambiente com novos desafios, que exige uma postura ética, valores culturais, comportamento ambiental, produtos mais limpos e legislação cada vez mais rigorosa em relação às questões sociais e ambientais, levando algumas organizações à construção da sustentabilidade. A necessidade de socializar as ações sustentáveis desenvolvidas na empresa, que garantam um diálogo transparente por meio de balanços sociais, relatórios de sustentabilidade e indicadores, consolida os mecanismos de divulgação. Para Aligleri, Aligleri e Kruglianskas (2009, p. 6), o público passou a expressar suas preocupações com o comportamento social das empresas, exigindo maior envolvimento delas na solução dos problemas, questionando o papel das empresas na sociedade.

De acordo com Almeida (2002), uma empresa para ser sustentável deve buscar e suas ações e decisões a ecoeficiência, procurando produzir mais e com melhor qualidade, gerando menos poluição e utilizando menos recursos naturais, sem perder de vista a responsabilidade social, condições sine-qua-non para alcançar o desenvolvimento sustentável.

\subsection{Relatórios de Sustentabilidade}

As organizações ao elaborarem seus relatórios, têm nas mãos um instrumento que possibilita consolidar um processo de melhoria sistêmica, além de dialogar com a sociedade sua intenção de transparência na busca do desenvolvimento sustentável. Relatórios de sustentabilidade são documentos descritivos de uma realidade e devem oferecer informações de forma integral da situação encontrada, seja positivas ou negativas. Elaborar relatórios de sustentabilidade é a prática de medir, divulgar e prestar contas para stakeholders internos e externos do desempenho organizacional visando o desenvolvimento sustentável (GRI, 2011). Para Veríssimo (2011), os relatórios de sustentabilidade são o resultado de um processo que visa identificar, mensurar e prestar contas sobre as ações das organizações com vistas à sustentabilidade.

Algumas empresas adotam relatórios com modelos próprios, outras organizações adotam modelos reconhecidos que definem exigibilidades próprias que servem para evidenciar as ações socioambientais implementadas. Segundo Castro, Siqueira e Macedo (2009), a abrangência do relatório diz respeito não só ao atendimento dos anseios dos stakeholders da organização, mas também à contemplação de todas as informações necessárias à análise do perfil socioambiental das empresas.

Os três modelos de relatórios de sustentabilidades mais usados no Brasil de acordo com a Ethos (2011) são: dois nacionais - um deles proposto pelo Instituto Brasileiro de Análises Sociais e Econômicas (Ibase) e o outro pelo Instituto Ethos de Empresas e Responsabilidade Social - e um internacional, sugerido pela Global Reporting Initiative (GRI). Todos visam definir as informações mínimas a serem publicadas para dar transparência às atividades da empresa. Relatório de sustentabilidade é um termo amplo, considerado sinônimo de outros relatórios cujo objetivo é uma descrição dos impactos econômicos, ambientais e sociais de uma empresa. Azevedo (2006) sugere que, seja sob a forma de balanços sociais, de relatórios socioambientais, ou ainda de relatórios de sustentabilidade, há no Brasil um número cada vez maior de empresas que divulgam publicamente suas ações sociais e ambientais.

O relatório da GRI oferece às empresas a possibilidade de publicarem seus relatórios de sustentabilidade em um padrão global, em um modelo organizado de indicadores e informações. Essa publicação oferece benefícios gerenciais para as empresas, visto que a GRI é apreciada pelos investidores e considerada ferramenta indispensável para as empresas que negociam seus títulos no mercado mundial (LEITE FILHO; PRATES; GUIMARAES, 2009).

A confiabilidade das informações perpassa pelo processo de elaboração do relatório, e quando instrumento tem por base a estrutura dos relatórios da GRI, se torna um grande atributo. As diretrizes para a elaboração de relatórios de sustentabilidade compreendem os Evolução dos Níveis de Aplicação de Relatórios de Sustentabilidade (GRI) de Empresas do ISE/Bovespa 
princípios, as orientações e os indicadores de desempenho (GRI, 2011). Alguns países por não possuírem modelos próprios de relatórios ambientais adotam os já legitimados, como o relatório GRI, a Grécia, por exemplo, não possui um modelo de indicadores próprio, assim faz uso do sistema EMAS - Sistema Comunitário de Ecogestão e Auditoria e GRI (PAPASPYROPOULOS; BLIOUMIS; CHRISTODOULOU, 2010).

As pesquisas realizadas com intuito de analisar as informações evidenciadas sobre o meio ambiente ganham espaço nas últimas décadas, mostrando que países e empresas vão gradativamente aumentando e melhorando as informações sobre a variável ambiental. Buscando se diferenciar dos concorrentes diversas empresas passam a fazer parte de índices de sustentabilidade em bolsas de valores (SILVA et al., 2009).

Para Vann e White (2004), expectativas mais elevadas da sociedade, das empresas e da resposta do mundo dos negócios, faz a necessidade óbvia para todos os tipos de organizações, notadamente contábeis, para ter conhecimento sobre relatórios de sustentabilidade. Significa incluir, conhecer as estruturas e sistemas para o desempenho de sustentabilidade, a contabilidade interna, o balanço social e a geração de relatórios de gestão, sobre o desempenho socioambiental para o relato às partes interessadas.

\subsubsection{Global Reporting Initiative - (GRI)}

Em 1999 foi elaborado as Diretrizes para Relatório de Sustentabilidade da Global Reporting Initiative (GRI), lançado em 2001. Em 2002 sofreu a primeira atualização, publicada em 2004 no Brasil, e outra atualização em 2006, chamada de G3, referenciando a terceira geração de indicadores. O lançamento da GRI G3 representou uma grande evolução para os relatórios de sustentabilidade, pela forma que foi revisado, que envolveu mais de 4000 pessoas de todo o mundo para o seu aperfeiçoamento. Para assegurar alto grau de qualidade técnica, credibilidade e relevância, a estrutura de relatórios de sustentabilidade da GRI é desenvolvida e continuamente melhorada por meio do engajamento de diversos stakeholder, que envolve organizações relatoras e especialistas que, juntos, desenvolvem e revisam o conteúdo da estrutura do relatório (GRI, 2011).

As diretrizes apresentadas pelo relatório abordam a sustentabilidade, buscando um equilíbrio entre o desempenho econômico, social e ambiental, o chamado triple botton line. As Diretrizes devem ser usadas como base para todo o processo de elaboração do relatório. Elas são o pilar que se apoiam todas as outras orientações para a elaboração de relatórios e apresentam o conteúdo considerado relevante para organizações de qualquer porte, setor ou localidade. As Diretrizes contêm princípios de relatório e orientações, assim como um modelo de conteúdo do relatório - incluindo indicadores - que delineia uma estrutura de divulgação que as organizações podem adotar de forma voluntária, flexível e progressiva (GRI, 2011).

Segundo Veríssimo (2011), o Global Reporting Initiative, é uma instituição independente com o propósito de desenvolver e disseminar diretrizes para os relatórios de sustentabilidade globalmente aplicáveis. Diretrizes estas que são atualizadas a cada dois anos, em revisões periódicas, para se adequar a mudanças e novas necessidades. Conforme as diretrizes para construção dos relatórios de sustentabilidade a missão da GRI é satisfazer essa necessidade, oferecendo uma estrutura confiável para a elaboração de relatórios de sustentabilidade, que possa ser usada por organizações de todos os tamanhos, setores e localidades (GRI, 2011).

A análise detalhada da estrutura da GRI mostra que o conjunto de diretrizes e indicadores proporciona a comparabilidade, credibilidade, periodicidade e legitimidade da informação na comunicação do desempenho social, ambiental e econômico das organizações (RIBEIRO; GOMES; SOUZA, 2011)

Para Bassetto (2010), a GRI estabelece princípios essenciais para a elaboração de relatórios equilibrados e abrangentes sobre o desempenho econômico, ambiental e social de 
uma organização, que representam as metas que os elaboradores tentam aplicar na elaboração de seus relatórios.

As diretrizes da GRI fornecem uma aplicação a nível internacional, proporcionando um sistema de comunicação comum para as organizações, para informar sobre seu desempenho econômico, ambiental e social (LAMPRINIDI; KUBO, 2008), no ponto de vista do setor público, o relatório GRI já aparece em pesquisas mais recentes (WILLIAMS, 2012).

\subsubsection{Forma de Gestão e Indicadores de Desempenho}

Segundo a GRI3 (2011) os indicadores de desempenho de sustentabilidade estão organizados nas categorias econômica, ambiental e social. Os indicadores sociais são subdivididos nas seguintes categorias: práticas trabalhistas, direitos humanos, sociedade e responsabilidade pelo produto. Cada categoria inclui informações sobre a forma de gestão e um conjunto correspondente de indicadores de desempenho essenciais e adicionais.

Os indicadores essenciais foram desenvolvidos por meio dos processos multistakeholders da GRI, que visam identificar os indicadores geralmente aplicáveis e considerados relevantes para a maioria das organizações. A organização deverá relatar os indicadores essenciais, a menos que eles demonstrem não estar alinhados aos princípios de relatório da GRI. Os indicadores adicionais representam práticas emergentes ou tratam de temas que podem ser relevantes para algumas organizações, mas não para outras (GRI, 2011).

Os 79 indicadores propostos pelo GRI 2009 envolvem questões sobre desempenho econômico, social e ambiental. Os nove indicadores de desempenho econômico envolvem aspectos sobre Desempenho Econômico Geral (4), Presença de Mercado (3) e Impactos Econômicos Indiretos (2). Os 40 indicadores de desempenho social contemplam Práticas de Mão-de-Obra e Trabalho Decente (14), Direitos Humanos (9) Desempenho em relação à Sociedade (8) e Responsabilidade pelo Produto (9). Enquanto os 30 indicadores de desempenho ambiental abordam aspectos sobre Consumo de Materiais (2); Energia (5); Água (3); Biodiversidade (5); Emissões, Efluentes e Resíduos (10); Produtos e Serviços (2); Conformidade (1); Transporte (1) e Geral, que contempla gastos e investimentos em proteção ambiental (1). Os suplementos setoriais complementam as diretrizes com interpretações e orientações sobre seu uso, em determinado setor e incluem indicadores de desempenho específicos do setor, não em substituição a elas (PEREIRA; FARIA; SOUZA, 2009).

As informações sobre a forma de gestão devem fornecer uma breve visão da abordagem da gestão da organização no que tange aos aspectos definidos sob cada categoria de indicador, visando estabelecer o contexto para informações sobre desempenho. A organização poderá estruturar suas informações sobre a forma de gestão de modo a cobrir a totalidade dos aspectos sob determinada categoria ou agrupar suas respostas para os aspectos de outra forma. Entretanto, as informações sobre a forma de gestão deverão tratar todos os aspectos relacionados a cada categoria, independentemente do formato ou agrupamento, procurando dar uma visão geral sobre os riscos e oportunidades que atingem a organização como um todo.

\subsubsection{Níveis de Aplicação da GRI}

Quando finalizado o relatório de sustentabilidade, deverá ser declarado pelos relatores o nível de aplicação da estrutura de relatório GRI. Essa declaração fornece aos relatores, uma visão ou possibilidades da aplicação da estrutura do relatório GRI ao longo do tempo e aos usuários transparência e clareza sobre até que ponto foi aplicado a estrutura do relatório na sua elaboração.

Declarar o nível de aplicação implica uma comunicação clara e transparentes de quais elementos da estrutura de relatórios da GRI foram aplicados na elaboração do relatório, os relatores iniciantes utilizam - nível $\mathrm{C}$, os relatores intermediários - nível $\mathrm{B}$, e os relatores avançados - nível A. Os critérios de relato encontrados em cada um dos níveis indicam a 
evolução da aplicação ou cobertura da estrutura de relatórios da GRI. A organização poderá autodeclarar um ponto a mais (+) em cada nível (por exemplo, $\mathrm{C}+, \mathrm{B}+, \mathrm{A}+$ ), caso tenha sido utilizada verificação externa (GRI, 2011).

O relatório deverá possibilitar na sua elaboração: clareza, exatidão, periodicidade, comparabilidade e confiabilidade. A preparação das informações deverá ser coerente com esses princípios, que orientam a elaboração, para assegurar a qualidade das informações relatadas, incluindo sua apresentação. Todos eles são fundamentais para uma transparência efetiva (GRI, 2011).

O Índice de Sustentabilidade Empresarial - ISE da Bovespa relaciona as empresas que atendem quesitos de sustentabilidade listada nessa carteira. Divulgar relatórios de sustentabilidade de acordo com o modelo da GRI é uma maneira das empresas que compõem o ISE evidenciar de forma transparente às partes interessadas seus projetos em ações socioambientais.

\section{3 Índice de Sustentabilidade Empresarial (ISE)}

Novas relações se estabelecem entre a empresa e a sociedade, construídas por meio da reputação e do comportamento sustentável, que as organizações propagam nos seus relatórios, que tem um efeito de valoração junto ao mercado. Em 1999 foi criado o Dow Jones Sustainability Group Index, em 2005 o Índice de Sustentabilidade Empresarial da Bovespa, que disponibilizam indicadores geral do desempenho das empresas, criando valor a médio e longo prazo.

O Índice de Sustentabilidade Empresarial (ISE) aplicado as empresa que negociam no mercado de ações da Bolsa de Valores de São Paulo (Bovespa), evidencia uma tendência das bolsas de valores no mundo. A BM\&FBovespa, em conjunto com várias instituições Abrapp, Anbid, Apimec, IBGC, IFC, Instituto ETHOS e Ministério do Meio Ambiente uniram esforços e criaram o índice de ações usado como referencial para os investimentos socialmente responsáveis e promover as boas práticas no meio empresarial. O Conselho do ISE considerou pertinente contratar uma instituição com expertise nessas questões - o Centro de Estudos de Sustentabilidade da Fundação Getúlio Vargas (CES-FGV), que desenvolveu um questionário para aferir o desempenho das companhias emissoras das ações (BM\&FBOVESPA, 2011).

O índice tem por objetivo promover boas práticas socioambientais para as organizações brasileiras e foi formulado utilizando o conceito do Triple Botton Line (TBL) que avalia, de forma integrada, as dimensões econômico-financeiras, sociais e ambientais das empresas (LINS; SILVA, 2009). O índice, de acordo com a BM\&FBovespa, atende a uma demanda crescente de investidores preocupados em aplicar seus recursos nos chamados investimentos socialmente responsáveis (BM\&FBOVESPA, 2011). O ISE serve como uma referência para indicar quais ações, dentre as negociadas pela Bovespa, são mais seguras a longo prazo tendem a representar menor risco ao investimento (LINS; SILVA, 2009). O ISE objetiva comparar o desempenho de empresas listadas na BM\&FBOVESPA sob os aspectos da sustentabilidade (DI AGUSTINI; VENDRAMETTO, 2011).

\section{Método de Pesquisa}

Em relação aos procedimentos técnicos, a referida pesquisa será do tipo bibliográfico e documental. Acevedo e Nohara (2007, p. 48), afirmam que o levantamento bibliográfico consiste na busca de estudos anteriores que já foram produzidos por outros cientistas e que geralmente são publicados em livros ou artigos científicos. Em relação à pesquisa documental, Gil (1995) afirma que se vale de materiais que não receberam ainda um 
tratamento analítico, ou que ainda podem ser reelaborados de acordo com os objetivos da pesquisa. Pretende-se realizar uma análise documental dos relatórios de sustentabilidade de empresas que declaram em conformidade as diretrizes GRI.

Quanto à abordagem o trabalho será qualitativo, segundo Creswell (2010 p. 206) os procedimentos qualitativos baseiam-se em dados de textos e imagens, e se valem de diferentes estratégias de investigação.

$\mathrm{O}$ universo da pesquisa foram as quarenta e cinco empresas brasileiras que participam do ISE da Bovespa, que relatam seus relatórios de sustentabilidade referenciadas pela GRI, evidenciando classificadas como autodeclaradas ou verificadas nos níveis: C, C+; B, B+ e A, A+, entre os anos de 2005 a 2010.

\subsection{Procedimentos de coleta dos dados}

A coleta de dados foi realizada no Report List GRI 2011, disponível no site da GRI, com o objetivo de verificar a evolução desses relatórios nas empresas listadas no ISE Bovespa, no Brasil e no mundo. A utilização de dados secundários possibilita a resolução de questões já conhecidas e explorar outras questões, ainda não investigadas (MARCONI; LAKATOS, 2007).

\subsection{Procedimentos de tratamento e análise dos dados}

O tratamento dos dados foi realizado por meio do software Excell utilizando a estatística descritiva e na análise foram considerados os seguintes tópicos: a evolução das empresas no mundo que adotam o modelo da GRI; a adoção do relatório no Brasil; o crescimento evolutivo no Índice de Sustentabilidade da Bovespa; os níveis de aplicação do relatório; e os níveis autodeclarados e verificados dos relatórios.

\section{Análise e Discussão dos Resultados}

A revisão da literatura evidencia que a publicação de relatórios de sustentabilidade caracteriza-se como boas práticas ambientais. O estudo mostra que as empresas pesquisadas, que fazem parte da carteira do ISE passaram por uma evolução nos níveis de aplicação da GRI.

A análise revela primeiramente ( Gráfico 1) um crescimento do número de empresas que relatam usando o modelo da GRI no mundo, sendo que no ano de 1999, somente 11 empresas faziam uso do modelo e em 2010 esse número cresceu para 1.837 empresas. A utilização da metodologia corresponde a um crescimento aproximado de $16600 \%$ em 11 anos, o que evidencia a legitimação do modelo no mundo.

Clarkson et al. (2008) afirma que as decisões voluntárias das empresas para preparar um relatório de acordo com o modelo da GRI, irá resultar em divulgação de um relatório que apresenta a indicação de um bom desempenho ambiental. A escolha do modelo do relatório e por ser uma decisão voluntária, acaba fazendo com que as empresas optem por modelos consolidados.

Já no Brasil o uso do modelo GRI corresponde a um crescimento de $13.300 \%$, de 2000 a 2010, como mostra o Gráfico 2. O relato por meio dessa estrutura está evoluindo de maneira significativa, mostrando que as empresas no Brasil estão acompanhando a tendência internacional na evidenciação das informações de sustentabilidade. 


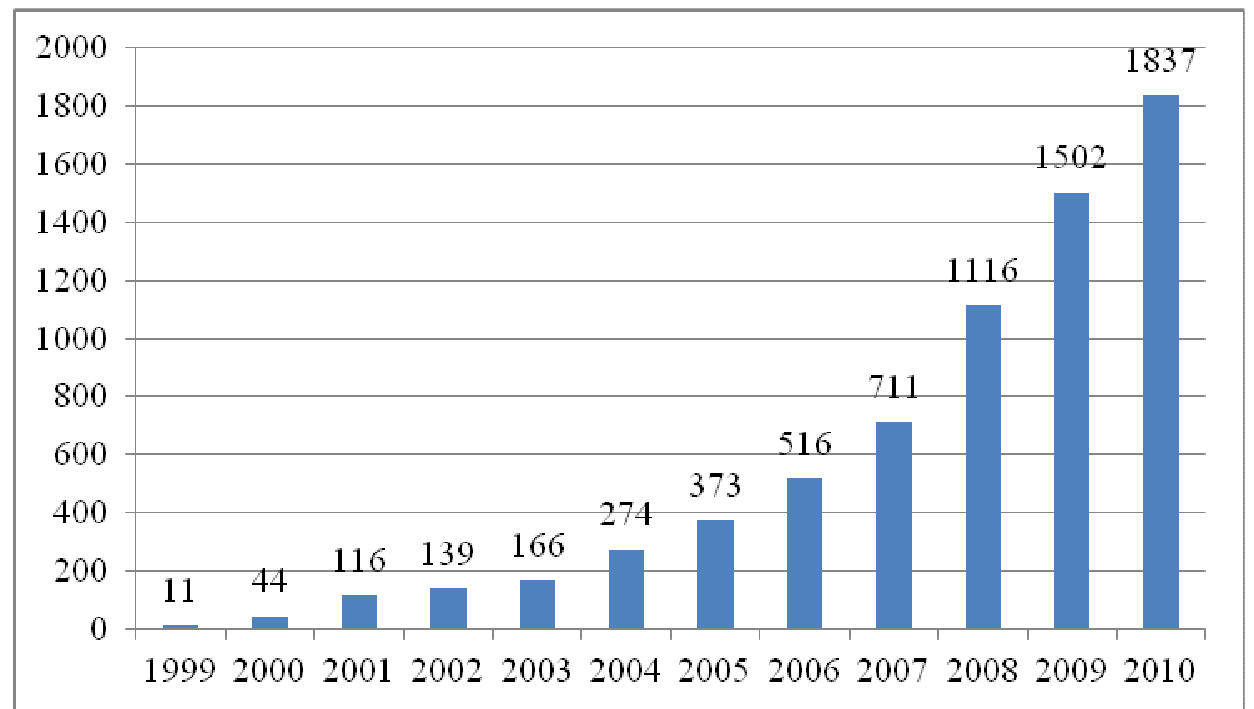

Fonte: Dados da pesquisa

\section{Gráfico 1 - Empresas no Mundo}

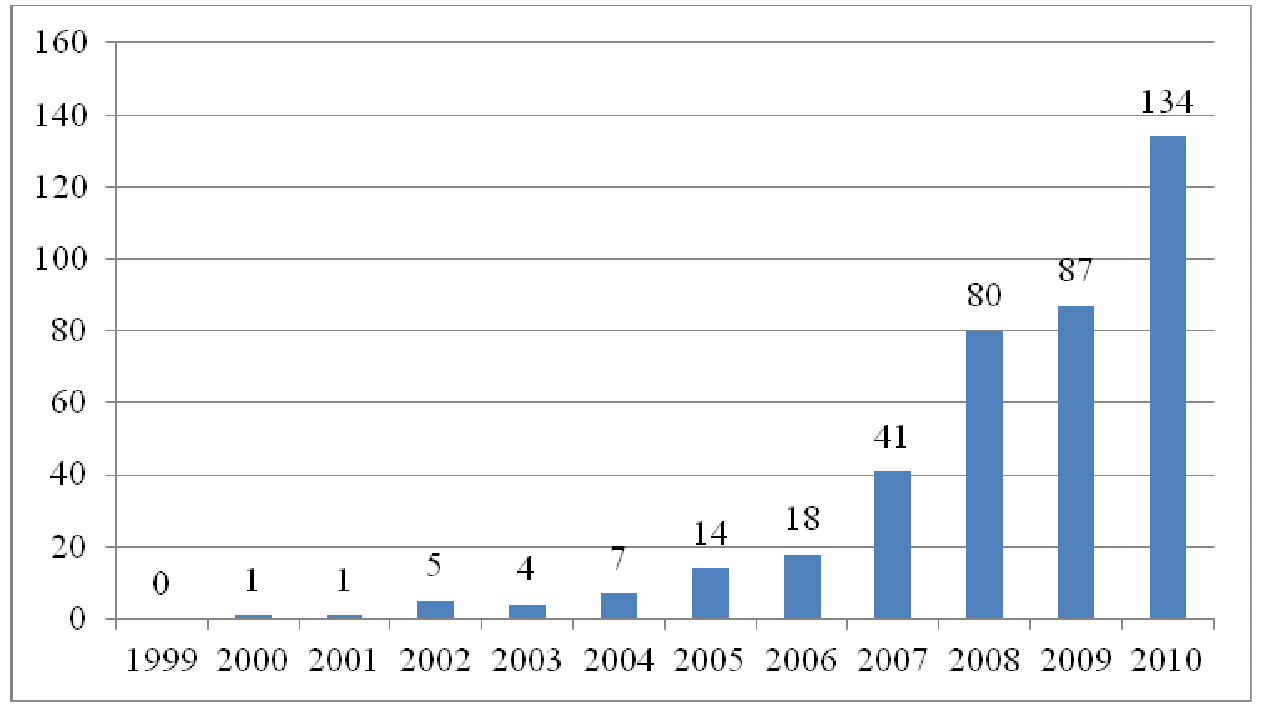

Fonte: Dados da pesquisa

Gráfico 2 - Empresas no Brasil

As empresas do ISE da BMF\&Bovespa também seguiram a mesma tendência na adoção ao modelo da GRI com crescimento significativo no período de 2005 a 2010, conforme Gráfico 3. Tal crescimento é decorrente do fato das empresas da carteira do ISE selecionadas dentre as emissoras das 200 ações mais líquidas por adequarem ao questionário do ISE (BMF\&BOVESPA, 2011), com 64 indicadores de sustentabilidade. 


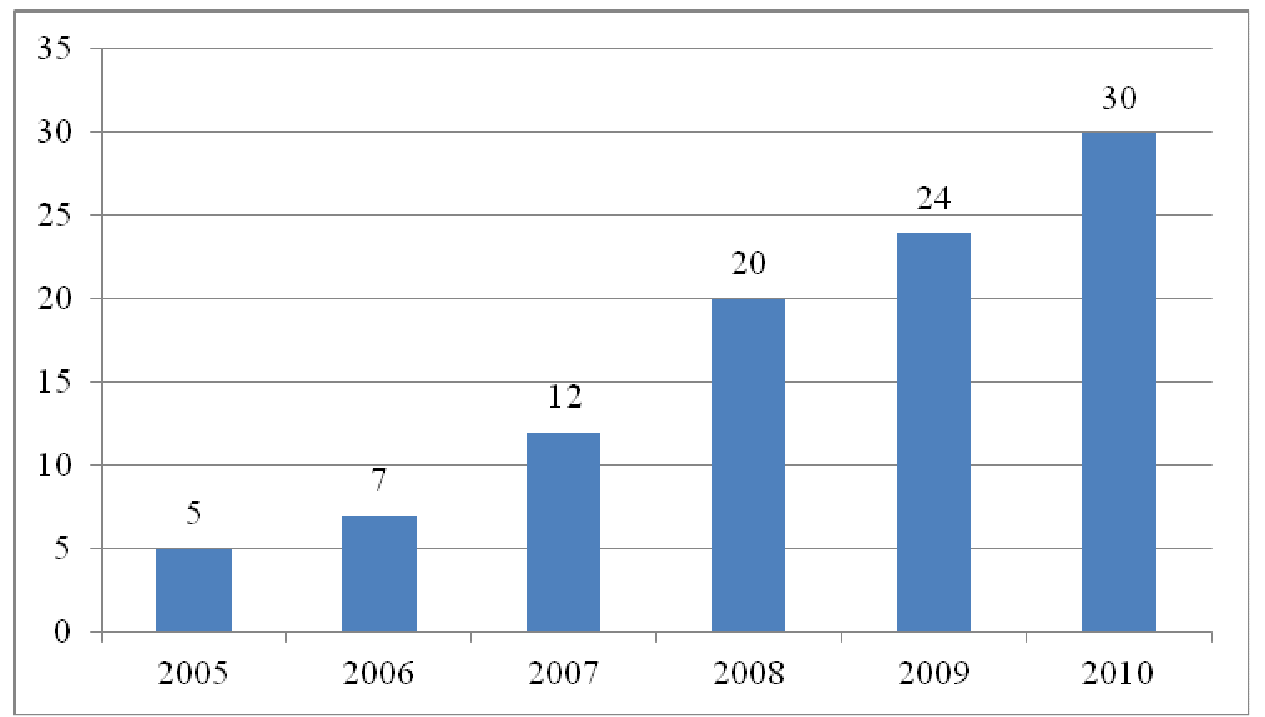

Gráfico 3 - Empresas nacionais atuantes no ISE

Fonte: Dados da pesquisa

O Gráfico 4 mostra a adoção das empresas do ISE ao modelo de relatório de sustentabilidade da GRI. Pode-se considerar muito significativo a implementação ao modelo, uma vez que o crescimento apresenta uma evolução de sete empresas em 2006 para 30 empresas em 2010. Percentualmente a adoção por ano apresenta $20 \%$ em 2006; $35 \%$ em 2007; 52\% em 2008; 54\% em 2009 e 66\% em 2010, de forma gradativa e ascendente, legitimando o modelo de relatório GRI, junto às empresas do ISE/Bovespa.

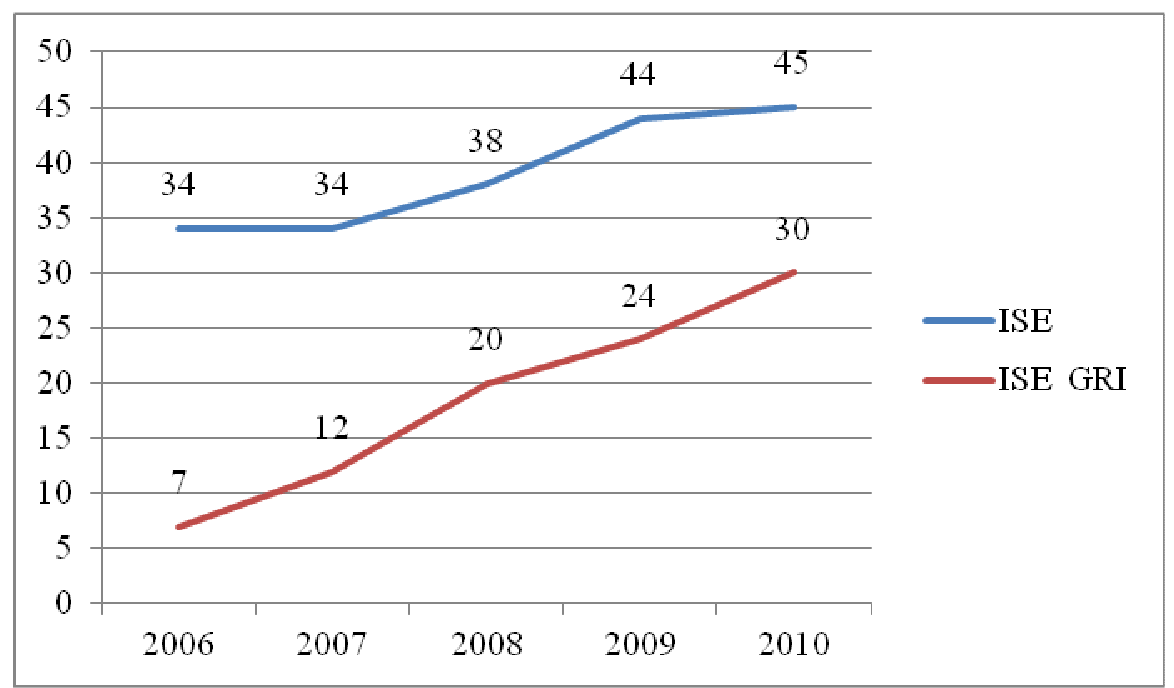

Gráfico 4 - Evolução das empresas do ISE com o modelo GRI

Fonte: Dados da pesquisa

O Gráfico 5 consolida as informações dos gráficos anteriores, oferecendo uma visualização integrada da adoção da GRI no mundo. De acordo com site da Global Reporting Initiative (2011), no ano de 2010 foram publicados, no mundo, cerca de 1837 relatórios de sustentabilidade, e no Brasil 134 relatórios, o que corresponde aproximadamente 7,3\% do total de relatórios da GRI no mundo. 


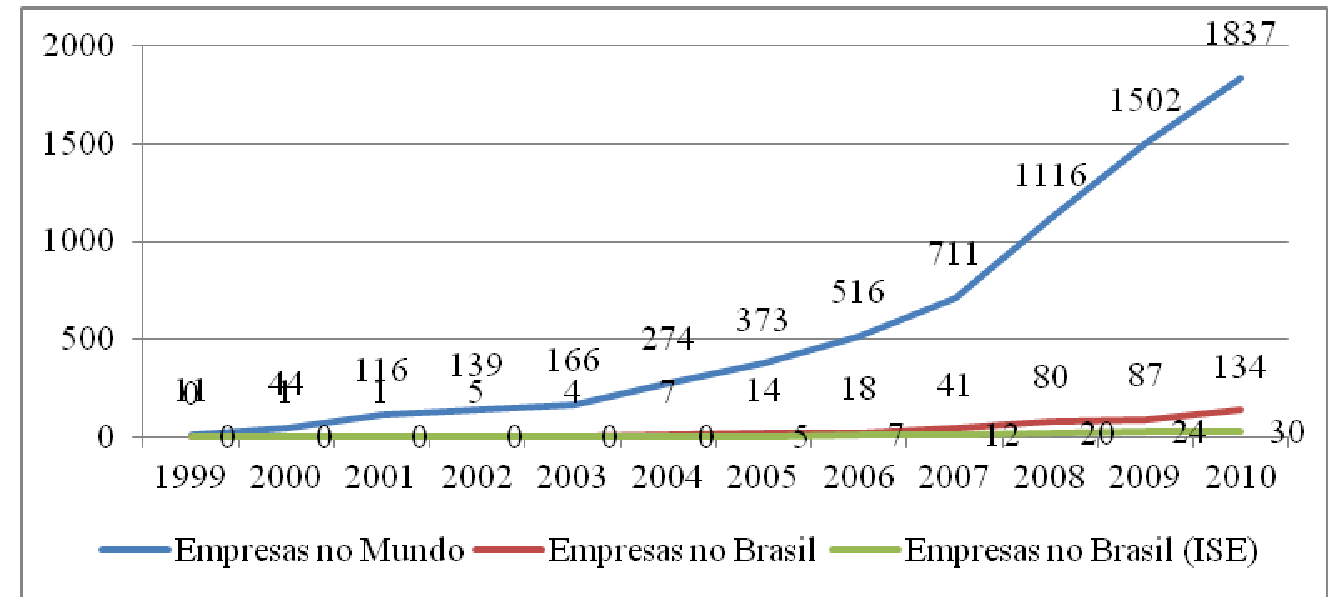

Gráfico 5 - Comparação das empresas que adotam as diretrizes da GRI Fonte: Dados da pesquisa

Outra consideração importante evidenciada na Tabela 1, apresenta a estrutura dos relatórios com evolução de seus níveis declarados em uso no mundo, confirmando o aumento de empresa que declaram seus níveis usando o modelo da GRI, no ano de 2006 era de 61, que representava proporcionalmente 12\% do número de empresas de 516, já em 2010 de 1432 que representa $78 \%$ proporcionalmente ao numero de empresas de 1837 . Contudo é possível perceber que à evolução dos níveis ocorre de forma gradativa em todos os níveis, demonstrando que as empresas ao preencherem seus relatórios, percorrem o caminho dessa evolução inicialmente se autodeclarando, uma vez que a verificação por terceiros ocorre em menor proporção.

Tabela 1 - Estrutura e Níveis dos relatórios do com verificação em uso no mundo

\begin{tabular}{|c|c|c|c|c|c|c|c|c|c|c|c|}
\hline \multicolumn{12}{|c|}{ Nível de Aplicação dos Relatórios no Mundo } \\
\hline Ano & $\begin{array}{c}\text { Em } \\
\text { Acordo }\end{array}$ & $\begin{array}{c}\text { Contém } \\
\text { somente } \\
\text { os } \\
\text { Indexados }\end{array}$ & $\mathrm{C}$ & $\mathrm{C}+$ & B & $\mathrm{B}+$ & A & $\mathrm{A}+$ & $\begin{array}{c}\text { Não } \\
\text { Declarados }\end{array}$ & $\begin{array}{c}\text { Não } \\
\text { Responderam }\end{array}$ & Total \\
\hline 2000 & & & & & & & & & & & 0 \\
\hline 2001 & & & & & & & & & & & 0 \\
\hline 2002 & 15 & 25 & & & & & & & & 99 & 139 \\
\hline 2003 & 44 & 100 & & & & & & & & 22 & 166 \\
\hline 2004 & 87 & 186 & & & & & & & & 1 & 274 \\
\hline 2005 & 143 & 224 & & & & & & & & 6 & 373 \\
\hline 2006 & 152 & 256 & 10 & 5 & 11 & 6 & 9 & 20 & 37 & 10 & 516 \\
\hline 2007 & 57 & 88 & 72 & 28 & 91 & 68 & 48 & 124 & 135 & & 711 \\
\hline 2008 & & & 166 & 27 & 151 & 116 & 83 & 216 & 333 & 24 & 1116 \\
\hline 2009 & & 2 & 270 & 70 & 230 & 141 & 120 & 300 & 369 & & 1502 \\
\hline 2010 & & & 324 & 93 & 295 & 196 & 147 & 377 & 405 & & 1837 \\
\hline
\end{tabular}

Fonte: Dados da pesquisa

Notas: Em Acordo - usou o Modelo GRI; Indexados - estão de Acordo e Indexados ao Modelo GRI; Modelo GRI 3 - Nível A ou A+; B ou B+; C ou C+; ÑD - Não Declarado; ÑR - Não Respondeu

A Tabela 2 mostra a evolução do Relatório da GRI e dos níveis de aplicação seqüencial do G3 C para o G3 A+, configurando a busca do nível mais alto de aplicação do relatório G3, da mesma forma uma evolução das empresas que informam como não Corrêa, R.; Souza, M. T. S.; Ribeiro, H. C. M.; Ruiz, M. S. 
declarados. No Brasil o número de empresas verificadas por terceiros é maior que as que se autodeclaram, o que pode ocorrer em função da necessidade das empresas legitimarem seus respectivos relatórios.

Tabela 2 - Estrutura e Níveis dos relatórios com verificação em uso no Brasil

\begin{tabular}{|c|c|c|c|c|c|c|c|c|c|c|c|}
\hline \multicolumn{12}{|c|}{ Nível de Aplicação dos Relatórios no Brasil } \\
\hline Ano & $\begin{array}{c}\text { Em } \\
\text { Acordo }\end{array}$ & $\begin{array}{c}\text { Contém } \\
\text { somente } \\
\text { os } \\
\text { Indexados }\end{array}$ & $\mathrm{C}$ & $\mathrm{C}+$ & $\mathrm{B}$ & $\mathrm{B}+$ & A & $\mathrm{A}+$ & $\begin{array}{c}\text { Não } \\
\text { Declarados }\end{array}$ & $\begin{array}{c}\text { Não } \\
\text { Responderam }\end{array}$ & Total \\
\hline 2000 & & & & & & & & & & & 0 \\
\hline 2001 & 1 & & & & & & & & & & 1 \\
\hline 2002 & 1 & 1 & & & & & & & & 3 & 5 \\
\hline 2003 & 2 & 1 & & & & & & & & 1 & 4 \\
\hline 2004 & 2 & 5 & & & & & & & & & 7 \\
\hline 2005 & 4 & 8 & & & & & & & & & 12 \\
\hline 2006 & 5 & 10 & 1 & & & & 1 & & & & 17 \\
\hline 2007 & 1 & 3 & 8 & 2 & 5 & 5 & 3 & 7 & 4 & & 38 \\
\hline 2008 & & & 19 & & 19 & 5 & 6 & 10 & 13 & & 72 \\
\hline 2009 & & & 23 & & 17 & 7 & 13 & 15 & 6 & & 81 \\
\hline 2010 & & & 34 & 4 & 30 & 9 & 13 & 21 & 23 & & 134 \\
\hline
\end{tabular}

Fonte: Dados da pesquisa

O Gráfico 6 mostra que, a partir de 2006, o modelo GRI na versão G3 começa a ser adotado pelas empresas do ISE da BM\&F Bovespa, que foi se adequando até chegar em 2010 com 30 empresas, das 45 atuantes no ISE, adotando o modelo, destas empresas quatro não declararam e uma empresa não evidenciou o nível do relatório. As versões G1 e G2 não estão mais sendo utilizadas e a versão G3 é o modelo predominante das 30 empresas que divulgam relatórios de sustentabilidade da carteira ISE/Bovespa.

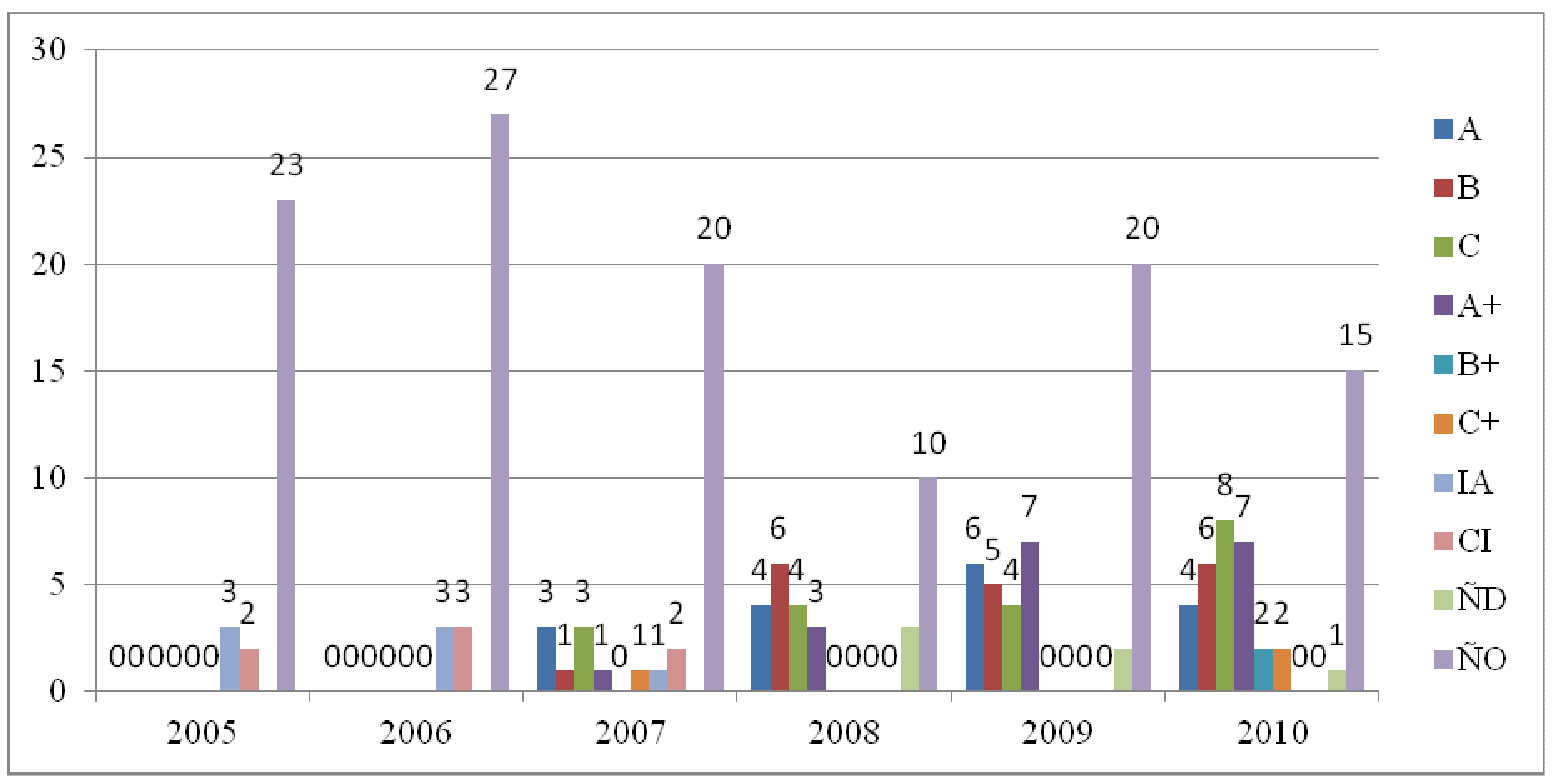

Fonte: Dados da pesquisa

Gráfico 6 - Níveis de aplicação nas empresas atuantes no ISE

Notas: Modelo GRI 3 - Nível A ou A+; B ou B+; C ou C+; IA - In Accordance; CI - Content Index Only; NDD Não Declarado; ÑO - Não Optante pelo Modelo GRI

Evolução dos Níveis de Aplicação de Relatórios de Sustentabilidade (GRI) de Empresas do ISE/Bovespa 
O Gráfico 6 ainda apresenta evolução dos níveis de aplicação dos relatórios da GRI das empresas do ISE, que pode ser verificado em 2007 com 1 empresas no Nível A+. Em 2010, houve um crescimento significativo com 7 relatórios no Nível A+, o melhor nível de evidenciação. Um estudo realizado em 2009, mostra que ainda é baixo o número de empresas no nível A+, nível mais alto de evidenciação. Portanto, mostra que ainda há melhorias a serem feitas pelas organizações para que se alcancem uma excelência na publicação de informações sustentáveis (LEITE FILHO; PRATES; GUIMARÃES, 2009). O que se comprova nesse estudo, uma vez que a busca pela excelência do nível A+ ainda se mostra tímida.

Enquanto que as empresas do ISE que não declararam a utilização do modelo de relatório da GRI, caiu de 23 em 2005 para 15 em 2010. O Gráfico também apresenta a verificação do relatório confirmando 11 empresas do ISE com Nível GRI+, o que significa uma evolução se comparada com o ano de 2009, em que apenas sete empresas foram verificadas, em um universo de 22 em 2009 e 30 em 2010.

A Tabela 3 apresenta um resumo dos níveis de aplicação e dos relatórios validados por verificação externa. O resultado das empresas que receberam verificação externa, em 2010 é de 12. Agora as empresas não optantes vêem em processo de redução, podendo representar que um número maior de empresas tem interesse em relatar pelo modelo GRI. Das 30 empresas que se autodeclararam usando o modelo GRI em 2010, uma delas não declarou o nível; 11 empresas se declaram nos níveis A; nove empresas no nível B; e também nove no nível C.

Tabela 3 - Estrutura e Níveis dos relatórios do ISE com verificação

\begin{tabular}{ccccccc}
\hline \multirow{2}{*}{ Modelos e Níveis } & \multicolumn{7}{c}{ Informações Integradas } \\
\cline { 2 - 7 } & 2005 & 2006 & 2007 & 2008 & 2009 & 2010 \\
\hline G1 & 0 & 0 & 0 & 0 & 0 & 0 \\
G2 & 5 & 6 & 3 & 0 & 0 & 0 \\
G3 & 0 & 1 & 9 & 19 & 23 & 30 \\
A & 0 & 1 & 3 & 4 & 5 & 4 \\
B & 0 & 0 & 1 & 6 & 5 & 6 \\
C & 0 & 0 & 3 & 4 & 4 & 7 \\
A+ & 0 & 0 & 1 & 3 & 8 & 7 \\
B+ & 0 & 0 & 0 & 0 & 0 & 3 \\
C+ & 0 & 0 & 1 & 0 & 0 & 2 \\
\hline
\end{tabular}

Fonte: Dados da pesquisa

O estudo aponta para um nível de aplicação de relatório mais alto, A+ em 2006 de 20 relatórios, chegando em 2010 com 377 empresas verificadas no mundo, sendo significativa essa evolução. Além de se autodeclararem, sofreram a verificação externa que validou os relatórios.

Estudo feito por Basseto (2010) sugere que a GRI é um modelo de evidenciação que está limitado aos aspectos qualitativos, uma vez que as próprias diretrizes não avançaram ainda para e um grau de detalhamento e de comprovação efetiva de resultados que possam ser mensuráveis. Esse resultado pode incentivar um aperfeiçoamento no modelo, uma vez que está em processo e adequação permanente, o que é verificado nas mudanças do modelo desde que foi criado.

Os resultados da pesquisa mostram que há um equilíbrio entre os três níveis de aplicação com aproximadamente 1/3 das empresas em cada um deles, ou seja, nos níveis A, B e C. Há desde empresas cobrindo apenas os indicadores essenciais, considerados relevantes 
para a maioria das organizações, assim como parte das empresas relatando além dos essenciais também os indicadores adicionais que representam práticas emergentes (GRI, 2011).

Ao se comparar os resultados deste estudo ao de Di Agustini e Vendrametto (2011), realizado por pesquisa não probabilística de conveniência exploratória, conclui-se que em sua quase totalidade os indicadores de sustentabilidade são relevantes nas decisões de investidores e que o ISE é o principal indicador de sustentabilidade das empresas listadas na BM\&FBovespa, fortalece o resultado do estudo, que evidenciou a importância de nível mais elevado de relatório GRI A de alto desempenho de sustentabilidade.

Um estudo feito em 2007 nas empresas listadas na bolsa de valor grega, por Papaspyropoulos, Blioumis e Christodoulou, (2010), mostrou que poucas corporações relatam as questões ambientais, mas dentre os cluster estudados, os que adotam diretrizes GRI têm indicação de um bom desempenho ambiental. O que corrobora com este estudo quando a importância de adoção do relatório no modelo GRI.

O trabalho de pesquisa que avaliou os relatórios de sustentabilidade no modelo GRI, conseguiu reforçar a importância de ferramentas, afirmando que têm alto potencial para instrumento de análise, mas é necessário incentivar melhorias em aspectos como padronização e transparência para que sejam usados com mais confiabilidade no processo de tomada de decisões (FERNANDES; SIQUEIRA; GOMES, 2010).

\section{Conclusão}

O objetivo do estudo foi investigar a evolução dos relatórios de sustentabilidade (GRI) e seus níveis de aplicação das empresas do ISE comparados com as demais empresas do Brasil e do mundo. Verificou-se tanto a adoção das empresas ao modelo da GRI, quanto a evolução nos níveis autodeclarados dos relatórios.

Os principais resultados mostram um processo evolutivo na adoção do modelo Global Reporting Initiative no mundo, bem como uma adoção das empresas a níveis crescentes de evolução do relatório de nível G3 C para o nível G3 A.

No Brasil esta adoção ao relatório também vem evoluindo, tanto na implantação como na evolução dos níveis dos relatórios. O número de empresas que validam seus relatórios por terceiros no país, pode ser em decorrência da emergência do tema no âmbito corporativo, ou seja, as empresas estão procurando legitimar seus relatórios de sustentabilidade por meio do maior nível $\mathrm{C}+, \mathrm{B}+\mathrm{e} \mathrm{A}+$, propiciando assim maior credibilidade das informações socioambientais aos seus stakeholders.

Quanto à evolução dos relatórios de sustentabilidade no modelo GRI no ISE, se consolida como modelo mais utilizado, 30 empresas de um total de 45, em 2010. Confirmando a consolidação e a legitimação da metodologia da GRI de divulgação de relatórios de sustentabilidade.

Como limitação, este estudo se deparou com um número reduzido de empresas no Brasil atuantes do ISE BM\&FBovespa, diferente de outros índices de sustentabilidade de bolsas internacionais que são compostos por um número maior de empresas em suas carteiras.

Sugere-se para futuros estudos uma analise de conteúdo desses relatórios de sustentabilidade para verificar com maior profundidade as principais diferenças entre os níveis de aplicação.

\section{Referências}

ACEVEDO, C. R.; NOHARA, J. J. Monografia no curso de administração: guia completo de conteúdo e forma. São Paulo: Atlas, 2007.

Evolução dos Níveis de Aplicação de Relatórios de Sustentabilidade (GRI) de Empresas do ISE/Bovespa 
ALIGLERI, L.; ALIGLERI, L. A.; KRUGLIANSKAS, I. Gestão socioambiental: responsabilidade e sustentabilidade do negócio. São Paulo: Atlas, 2009.

ALMEIDA, F. O bom negócio da sustentabilidade. Rio de Janeiro: Nova Fronteira, 2002.

AZEVEDO, A. L. V. Indicadores de sustentabilidade empresarial no Brasil: uma avaliação do Relatório do CEBDS. Revista Iberoamericana de Economía Ecológica v. 5, p. 75-93. 2006.

BASSETTO, L. I. A incorporação da responsabilidade social e sustentabilidade: um estudo baseado no relatório de gestão 2005 da companhia paranaense de energia - COPEL. Gestão \& Produção, São Carlos, v. 17, n. 3, p. 639-651, 2010.

BM\&FBOVESPA. Índice de Sustentabilidade Empresarial. Disponível em <http://www.bmfbovespa.com.br/novo-valor $>$. Acesso em: 26 mar. 2011.

CASTRO, F. A. R.; SIQUEIRA, J. R. M.; MACEDO, M. A. S. Indicadores Ambientais Essenciais: Uma Análise da Sua Utilização nos Relatórios de Sustentabilidade das Empresas do Setor de Energia Elétrica Sul Americano, Elaborados pela Versão "G3" da Global Reporting Initiative. 1st South American Congress on Social and Environmental Accounting Research - CSEAR 2009.

CLARKSON, P. M. et al. Revisiting the relation between environmental performance and environmental disclosure: an empirical analysis. Accounting Organizations and Society. v, 33, n. 4-5, p. 303-327, 2008.

COMISSÃO MUNDIAL SOBRE O MEIO AMBIENTE E DESENVOLVIMENTO. Nosso Futuro em Comum. 2. ed. Rio de Janeiro: FGV, 1991.

CRESWELL, J. W. Projeto de pesquisa: métodos qualitativo, quantitativo e misto. Porto Alegre: Artmed, 2010.

DI AGUSTINI, C. A.,VENDRAMETTO, L. P. Análise de Requisitos Científicos com a Dimensão Ambiental do ISE da BM\&FBOVESPA e de Indicadores de Sustentabilidade Publicados nos Relatórios de Sustentabilidade/Anuais das Empresas. 3rd International Workshp Advances In Cleaner Production. Cleaner Production Initiatives and Challenges for a Sustainable Word. São Paulo; 2011. Disponível em<http://www.advancesincleanerproduction.net/>. Acesso em: 15 jun. 2011.

FERNANDES, F. S.; SIQUEIRA, J. R. M.; GOMES, M. Z.. A decomposição do Modelo da Global Reporting Initiative (GRI), para Avaliação de Relatório de Sustentabilidade. Revista do BNDES, n. 34, p.101-132, 2010.

GIL, A. C. Métodos e técnicas de pesquisa social. São Paulo: Atlas, 1995.

GRI, Global Reporting Initiative. Diretrizes G3. Disponível em: 〈www.globalreporting.org> Acesso em: 14 mar. 2011.

GRI - Global Reporting Initiative. Report List. Disponível em: <http://www.globalreporting.org/ReportServices/GRIReportsList/> Acesso em: 12 abr. 2011

Corrêa, R.; Souza, M. T. S.; Ribeiro, H. C. M.; Ruiz, M. S. 
GRI - Global Reporting Initiative. Home. Disponível em: <http://www.globalreporting.org/Home/AboutRFPRT.htm >Acesso em: 13 abr. 2011

GRI - Global Reporting Initiative. Diretrizes para Relatório de Sustentabilidade de GRI 2006. Disponível em <http://www.ethos.org.br/_Uniethos/documents/gri_g3./>. Acesso em 10 mar. 2011.

INSTITUTO ETHOS. Parceria Ethos/GRI. Disponível em: <http://www.ethos.org.br/> Acesso em: 18 mar. 2011.

LAMPRINIDI, S.; KUBO, N. Debate: The Global Reporting Initiative and Public Agencies. Public Money \& Management, p. 326-329, 2008.

LEITE FILHO, G. A.; PRATES, L. A.; GUIMARÃES T. N. Níveis de Evidenciação dos Relatórios de Sustentabilidade das Empresas Brasileiras A+ do Global Reporting Initiative (GRI) no Ano de 2007. In: Associação Nacional de Pós-Graduação e Pesquisa em Administração. XXXIII EnANPAD. Anais Eletrônicos... Rio de Janeiro: ANPAD, 2009. Disponível em: 〈http://www.anpad.org.br/>. Acesso em: 02 fev.2011.

LINS, L. S.; SILVA, R. N. S. Responsabilidade Sócio-Ambiental ou Greenwash: Uma Avaliação com Base nos Relatórios de Sustentabilidade Ambiental. Sociedade, Contabilidade e Gestão, v. 4, n. 1, 2009.

MARCONI, M. de A.; LAKATOS, E. M. Metodologia do trabalho científico: procedimentos básicos, pesquisa bibliográfica, projeto e relatório e publicações e trabalhos científicos. São Paulo: Atlas, 2007.

PAPASPYROPOULOS, K. G.; BLIOUMIS V.; CHRISTODOULOU, A. S. Environmetal reporting in Greece: The Athens stock exchange. African Journal of Business Management v. 4, p. 2693-2704, 2010.

PEREIRA, R. S.; FARIA, A. C.; SOUZA, M. T. S. Análise de indicadores de sustentabilidade no segmento químico e petroquímico. In: Associação Nacional de Pós-Graduação e Pesquisa em Administração. XXXIII EnANPAD. Anais Eletrônicos... Rio de Janeiro: ANPAD, 2009. Disponível em: 〈http://www.anpad.org.br/>. Acesso em: 02 fev. 2011.

RIBEIRO, H. C. M.; GOMES, N. B.; SOUZA. Evidenciação das Informações sobre Emissões de GEE das Empresas Listadas no ISE Bovespa. In: SIMPÓSIO DE ADMINISTRAÇÃO DA PRODUÇÃO, LOGÍSTICA E OPERAÇÕES INTERNACIONAIS. XIV SIMPÓI. Anais Eletrônicos... São Paulo: EAESP/FGV, 2011. Disponível em: <http://www.simpoi.fgvsp.br/>. Acesso em: 20 jul. 2011.

SACHS, I. Desenvolvimento sustentável, bioindustrialização descentralizada e novas configurações rural-urbanas. Os casos da Índia e do Brasil. IN: VIEIRA, P.F.; WEBER, (Orgs.) Gestão de Recursos naturais renováveis e desenvolvimento: novos desafios para a pesquisa ambiental. São Paulo: Cortez, 1997

SILVA, J. O. et al. Evidenciação dos Custos Ambientais nas Empresas que Compõem o Índice de Sustentabilidade Empresarial. In: Encontro Nacional e Internacional sobre Gestão 
Empresarial e Meio Ambiente. XI Engema. Anais Eletrônicos... Fortaleza: Unifor, 2009. Disponível em: <http://engemas.net/>. Acesso em 12 jun. 2011.

VANN, J. W.; WHITE G. B.. Sustainability Reporting in the Accounting Curriculum. Journal of Business \& Economics Research, v. 2, n. 12, 2004.

VERÍSSIMO, C. M. O. Auditoria e Relatórios de Sustentabilidade. Disponível em <www.aeca.es/pub/on_line/comunicaciones_xivencuentroaeca/> Acesso em: 11 abr. 2011.

COMISSÃO MUNDIAL SOBRE O MEIO AMBIENTE E DESENVOLVIMENTO. Nosso Futuro Comum. Rio de Janeiro: FGV, 1991.

WILLIAMS, B. GRI reporting guidlines in the local government sector - are they being utilized? Disponível em: <http://www.utas.edu.au/_data/assets/pdf_file/0008/188441/Williams.pdf $>$. Acesso em: 20 jun. 2012. 